\title{
Waiting for the Second (Non)-Covid-19 Wave: Variations in Volume of Emergency Surgeries and of Emergency Department Accesses in a Third Level Hospital in Milan, Lombardy, During the Outbreak
}

\author{
Laura Castoldi ( $\square$ laucast@tiscali.it) \\ Fondazione IRCCS Ca' Granda Ospedale Maggiore Policlinico, Milano \\ Monica Solbiati \\ Fondazione IRCCS Ca' Granda Ospedale Maggiore Policlinico, Milano \\ Giorgio Costantino \\ Fondazione IRCCS Ca' Granda Ospedale Maggiore Policlinico, Milano \\ Elena Casiraghi \\ Anacleto Lab, Computer Science Department, Università degli Studi di Milano
}

\section{Research Article}

Keywords: Coronavirus, COVID-19, emergency surgery, ED attendances, ED overcrowding

Posted Date: October 26th, 2020

DOl: https://doi.org/10.21203/rs.3.rs-92599/v1

License: (c) (1) This work is licensed under a Creative Commons Attribution 4.0 International License. Read Full License 


\section{Abstract}

Introduction: During the recent outbreak of COVID-19 (Corona VIrus Diseases 2019), Lombardy was the Italian region most affected, with 87,000 patients and 15,876 deaths (until May 26). Since February 22, well before the Government declared the state of emergency, a huge reduction of emergency surgeries was seen in Lombardy Hospitals, with a generalized drop of attendances in the Emergency Departments (EDs).

Study Objective: The aim of this study is to report the experience of the ED of a third-level hospital in downtown Milan, Lombardy (IRCCS Foundation Cà Granda Ospedale Maggiore Policlinico), and try to explain the causes of the observed phenomena.

Methods: A retrospective, observational study was performed assessing the volume of emergency surgeries and of the attendances in the ED during the course of the pandemic, i.e. immediately before, during and after progressive community lockdown in response to the COVID-19 pandemic, comparing the same time periods in 2019 .

Results: Compared to the previous year, in 2020 a significant overall drop of emergency surgeries $(60 \%, p<0.002)$ and of ED attendances (66\%, $\mathrm{p} \cong 0)$ was observed. The drop was significant for medical (40\%), surgical (74\%), specialist fast track (92\%), and psychiatric (60\%) complaints, for domestic violence accesses (59\%) and for patients who left the ED without being seen (LWBS) (76\%). Conversely, deaths raised by $196 \%$.

Conclusion: During the COVID-19 outbreak the volume of urgent surgeries and the volume of patients accessing ED dropped. At the moment, it is not known if mortality of people who did not seek care increased during the pandemic. Further studies are needed to try to understand if such reductions during the COVID-19 pandemic will result in a rebound of patients left untreated, or in unwanted consequences on population health.

\section{Introduction}

The outbreak of COVID-19 started in Whuan, Cina, in December 2019 and quickly spread beyond the borders of the People's Republic of China. The World Health Organization (WHO) declared COVID-19 a worldwide pandemic on March 11, when more than 118,000 people were affected by Severe acute respiratory syndrome-related coronavirus-2 (SARS-CoV-2) all over the world. In Italy, the first patient tested positive for SARS-CoV-2 was admitted to the intensive care unit of the Codogno Hospital, a town near Lodi (Lombardy), on February 20. On February 22, the Government of Lombardy instituted an emergency task force to face the emergency, and established containment measures by quarantining several towns near Codogno (the so-called "red zones"), where several COVID-19 clusters emerged. In fourteen days, ICU admissions were more than 550 and hospital admission 2,217 [1]. Due to the rapid spread of infection, on March 8 Lombardy was quarantined and self-isolation measures were instituted to slow down virus transmission. As on April 20, more than 19,000 COVID-19 patients were admitted to Lombardy hospitals [2] .

Of note, on March 8 the Lombardy Government established the "Hub and Spoke" model: some hospitals were designated to be hubs for healthcare timedependent diseases, such as polytrauma, and cardiovascular and neurological emergencies [3]. The Policlinico Hospital was temporarily not allowed to admit polytrauma patients, but arranged emergency rooms, emergency operating area (according to subsequent recommendations of international surgical societies) [4-6], surgical non-intensive care ward, and intensive care unit (ICU) beds for non-COVID patients, in adjunct to areas for infectious or suspected COVID-19 patients.

Since February 22, the Ospedale Maggiore Policlinico emergency department started to prepare for COVID-19 patients, with logistic measures and new triage rules. All elective surgeries were stopped, and surgeons were reallocated in the ED and COVID-19 wards to take care of the less critical patients. At the same time, a drop in ED attendances for non-COVID-19 diseases, especially in patients with surgical complaints, was observed. The reduction inversely followed the increase of COVID-19 patients.

The aim of this paper is to quantify the extent and the reasons of such reductions, assess the characteristics of the potentially surgical patients that stayed away from ED, and analyse how surgical emergencies could have been managed without ED access.

\section{Methods}

A retrospective, observational study was performed, assessing all the emergency surgeries performed and all the attendances at the ED in a level III university hospital immediately before, during and after progressive community lockdown in response to the COVID-19 pandemic. Using an anonymous database, the data on ED attendances were collected and analyzed along four time periods: Period 1 (February 21-March 8; 16 days in 2020, leap year; 15 days in 2019), when the first patient was admitted to the Codogno Hospital and ten small town near Milan were quarantined, Period 2 (March 9, until March 21; 14 days), starting of the lockdown in Lombardy, and in 14 provinces in Piemonte, Veneto, Emilia Romagna, and Marche, Period 3 (March 22, until April 21; 32 days), from further enlargement of lockdown to the entire Italian nation, with shutting down of all non-necessary businesses and industries, and Period 4 (April 22, until May 12; 19 days), when attendances of COVID-19 patients decreased and it was clear that the national lockdown would have been attenuated, as it was effectively announced on April 26 (the beginning of the so-called "Phase 2").

For every period, attendances at the ED were split out according to sub-specialties: medicine, surgery, specialist fast tracks (ophthalmology, otolaryngology, traumatology, and urology), psychiatric examinations and attendances for domestic violence. Deaths in the ED and patients who left the ED without being seen by a physician (LWBS) were collected. All the data were compared with the same time periods in 2019.

In the same way, the emergency surgical interventions of the same time periods in 2020 and in 2019 were compared. 
Data are presented as means, standard errors (SE), and 95\% studentized confidence intervals (Cl). All the $95 \%$ studentized confidence interval for the means were computed by 2500 bootstrap iterations.

Wilcoxon rank signed test at the 0.05 significance level was used to assess the difference in the per-day access distributions corresponding to the following groups: medicine, surgery, specialist fast track, psychiatry, domestic violence, people who left the ED without being seen (LWBS), and deaths.

For each category, drop percentages of the number of events in $2020\left(x_{2020}\right)$ with respect to the number of events in 2019 ( $\left.x_{2019}\right)$ were computed as: $\operatorname{drop} \%=\operatorname{abs}\left(\mathrm{x}_{2019}-\mathrm{x}_{2020}\right) / \mathrm{x}_{2020}$

The Matlab software (The MathWorks, Inc., Natick, MA, USA) was used for data analysis and to generate the plots.

\section{Results}

Compared to the same period in 2019, in 2020 the study showed an overall drastic reduction in ED attendances for non-COVID-19 diseases starting from February 22 ( period 1), namely 48\% (3,108 vs 1,607). Figure 1 shows the daily counts of accesses in 2020 compared to 2019.

This trend went on in the second and in the third period, with a total of 5,307 ED attendances in 2020 vs 15,464 in 2019, with a drop of 61\% (Table 1).

\section{Table 1}




\begin{tabular}{|c|c|c|c|c|c|c|c|c|c|c|c|}
\hline \multicolumn{2}{|l|}{ Period } & \multicolumn{2}{|l|}{1} & \multicolumn{2}{|l|}{2} & \multicolumn{2}{|l|}{3} & \multicolumn{2}{|l|}{4} & \multicolumn{2}{|l|}{ Total } \\
\hline & & $\begin{array}{l}\text { Daily } \\
\text { accesses }\end{array}$ & $95 \% \mathrm{Cl}$ & $\begin{array}{l}\text { Daily } \\
\text { accesses }\end{array}$ & $95 \% \mathrm{Cl}$ & $\begin{array}{l}\text { Daily } \\
\text { accesses }\end{array}$ & $95 \% \mathrm{Cl}$ & $\begin{array}{l}\text { Daily } \\
\text { accesses }\end{array}$ & $95 \% \mathrm{Cl}$ & $\begin{array}{l}\text { Daily } \\
\text { accesses }\end{array}$ & $95 \% \mathrm{Cl}$ \\
\hline & & $($ mean $\pm S E)$ & & $($ mean $\pm S E)$ & & (mean $\pm S E)$ & & $($ mean $\pm S E)$ & & $($ mean $\pm S E)$ & \\
\hline \multirow{3}{*}{ Medicine } & 2019 & $78 \pm 1.86$ & $\begin{array}{l}{[73,} \\
82]\end{array}$ & $79 \pm 1.37$ & {$[76,82]$} & $76 \pm 1.58$ & {$[73,80]$} & $76 \pm 2.52$ & {$[69,80]$} & $77 \pm 0.95$ & {$[75,79]$} \\
\hline & 2020 & $62 \pm 2.55$ & {$[58,71]$} & $42 \pm 1.68$ & {$[39,46]$} & $40 \pm 1.68$ & {$[37,43]$} & $45 \pm 2$ & {$[41,49]$} & $46 \pm 1.35$ & {$[43,49]$} \\
\hline & $\begin{array}{l}\% \\
\text { drop }\end{array}$ & $21 \pm 3.35$ & {$[7,26]$} & $47 \pm 0.86$ & {$[44,48]$} & $49 \pm 1.32$ & {$[45,51]$} & $40 \pm 0.8$ & {$[39,42]$} & $40 \pm 1.34$ & {$[38,43]$} \\
\hline \multirow[t]{3}{*}{ Surgery } & 2019 & $30 \pm 1.49$ & {$[27,33]$} & $28 \pm 1.18$ & {$[25,31]$} & $28 \pm 0.95$ & {$[26,30]$} & $28 \pm 1.25$ & {$[26,32]$} & $29 \pm 0.59$ & {$[27,30]$} \\
\hline & 2020 & $14 \pm 1.88$ & {$[8,17]$} & $5 \pm 0.59$ & {$[3,6]$} & $3 \pm 0.35$ & {$[3,4]$} & $11 \pm 0.76$ & {$[9,12]$} & $8 \pm 0.66$ & {$[6,9]$} \\
\hline & $\begin{array}{l}\% \\
\text { drop }\end{array}$ & $56 \pm 2.51$ & {$[51,62]$} & $85 \pm 0.7$ & {$[83,86]$} & $88 \pm 0.53$ & {$[87,89]$} & $63 \pm 1.45$ & {$[58,65]$} & $74 \pm 1.61$ & {$[71,78]$} \\
\hline \multirow{3}{*}{$\begin{array}{l}\text { Spec.fast } \\
\text { track }\end{array}$} & 2019 & $64 \pm 2.4$ & {$[59,71]$} & $65 \pm 1.97$ & {$[61,69]$} & $63 \pm 2.62$ & {$[58,68]$} & $62 \pm 3.55$ & {$[53,69]$} & $63 \pm 1.41$ & {$[61,66]$} \\
\hline & 2020 & $12 \pm 1.74$ & {$[8,15]$} & $3 \pm 0.51$ & {$[1,4]$} & $3 \pm 0.31$ & {$[2,3]$} & $5 \pm 0.5$ & {$[4,6]$} & $5 \pm 0.55$ & {$[4,6]$} \\
\hline & $\begin{array}{l}\% \\
\text { drop }\end{array}$ & $81 \pm 2.33$ & {$[76,87]$} & $96 \pm 0.35$ & {$[95,97]$} & $96 \pm 0.28$ & {$[95,96]$} & $92 \pm 0.58$ & {$[91,93]$} & $92 \pm 0.77$ & {$[91,94]$} \\
\hline \multirow[t]{3}{*}{ Psychiatry } & 2019 & $5 \pm 0.44$ & {$[4,5]$} & $4 \pm 0.44$ & {$[3,5]$} & $4 \pm 0.38$ & {$[4,5]$} & $5 \pm 0.67$ & {$[3,6]$} & $4 \pm 0.24$ & {$[4,5]$} \\
\hline & 2020 & $3 \pm 0.37$ & {$[2,4]$} & $2 \pm 0.37$ & {$[1,2]$} & $1 \pm 0.2$ & {$[1,1]$} & $2 \pm 0.31$ & {$[1,3]$} & $2 \pm 0.16$ & {$[1,2]$} \\
\hline & $\begin{array}{l}\% \\
\text { drop }\end{array}$ & $34 \pm 7.03$ & {$[20,52]$} & $50 \pm 4.11$ & {$[43,69]$} & $74 \pm 2.46$ & {$[69,79]$} & $65 \pm 3.83$ & {$[54,71]$} & $60 \pm 2.38$ & {$[56,66]$} \\
\hline Domestic & \multirow[t]{2}{*}{2019} & 29 & \multirow{2}{*}{$\begin{array}{l}{[1.1} \\
2.47]\end{array}$} & 36 & \multirow{2}{*}{$\begin{array}{l}{[0.52,} \\
3.61]\end{array}$} & 51 & \multirow{2}{*}{$\begin{array}{l}{[0.83,} \\
2.21]\end{array}$} & 24 & \multirow{2}{*}{$\begin{array}{l}{[0.36,} \\
1.68]\end{array}$} & 140 & \multirow{2}{*}{$\begin{array}{l}{[1.34,} \\
2.18]\end{array}$} \\
\hline \multirow[t]{6}{*}{ Violence } & & $1.93 \pm 0.29$ & & $2.57 \pm 0.6$ & & $1.70 \pm 0.26$ & & $1.33 \pm 0.26$ & & $1.75 \pm 0.17$ & \\
\hline & \multirow[t]{2}{*}{2020} & 22 & \multirow{2}{*}{$\begin{array}{l}{[0.75,} \\
2.04]\end{array}$} & 5 & \multirow{2}{*}{$\begin{array}{l}{[0.05,} \\
0.61]\end{array}$} & 8 & \multirow{2}{*}{$\begin{array}{l}{[0.04,} \\
0.45]\end{array}$} & 22 & \multirow{2}{*}{$\begin{array}{l}{[0.51,} \\
1.52]\end{array}$} & 57 & \multirow{2}{*}{$\begin{array}{l}{[0.54,} \\
0.86]\end{array}$} \\
\hline & & $1.38 \pm 0.27$ & & $0.36 \pm 0.16$ & & $0.27 \pm 0.09$ & & $1.22 \pm 0.26$ & & $0.70 \pm 0.11$ & \\
\hline & \multirow{3}{*}{$\begin{array}{l}\% \\
\text { drop }\end{array}$} & 24 & \multirow{3}{*}{$\begin{array}{l}{[-427.48} \\
4673.33]\end{array}$} & 90 & \multirow{3}{*}{$\begin{array}{l}\text { [82.41, } \\
91.2]\end{array}$} & 80 & \multirow{3}{*}{$\begin{array}{l}\text { [80.96, } \\
89.48]\end{array}$} & 10 & \multirow{3}{*}{$\begin{array}{l}{[-10.19,} \\
31.67]\end{array}$} & 60 & \multirow{3}{*}{$\begin{array}{l}{[47.45,} \\
62]\end{array}$} \\
\hline & & $-160 \pm$ & & & & & & $10 \pm 8.92$ & & & \\
\hline & & & & $86 \pm 2.04$ & & $85 \pm 1.66$ & & & & $55 \pm 4.38$ & \\
\hline Deaths & 2019 & 4 & {$[0,0.41]$} & 5 & {$[0.01$,} & 8 & {$[0,0.40]$} & 6 & {$[0,0.48]$} & 23 & {$[0.04$,} \\
\hline & & $0.27 \pm 0.11$ & & $0.36 \pm 0.16$ & & $0.27 \pm 0.09$ & & $0.33 \pm 0.13$ & & $0.29 \pm 0.06$ & \\
\hline & 2020 & 6 & {$[0,0.62]$} & 19 & {$[0.54$,} & 27 & {$[0.54$,} & 16 & {$[0.44$,} & 68 & {$[0.57$} \\
\hline & & $0.38 \pm 0.15$ & & $1.36 \pm 0.32$ & & $0.90 \pm 0.16$ & & $0.89 \pm 0.18$ & & $0.84 \pm 0.1$ & \\
\hline & $\%$ & 50 & [-239.76, & 280 & [187.93, & 238 & {$[196.93$,} & 167 & [106.99, & 196 & {$[172.36$} \\
\hline & & $89 \pm 50.37$ & & $\begin{array}{l}348 \pm \\
78.77\end{array}$ & & $\begin{array}{l}332 \pm \\
48.04\end{array}$ & & $\begin{array}{l}248 \pm \\
55.27\end{array}$ & & $\begin{array}{l}259 \pm \\
26.77\end{array}$ & \\
\hline
\end{tabular}

For surgical accesses, the mean drop was $56 \%, 85 \%$ and $88 \%$ through period 1,2 , and 3 , respectively. Considering all the four periods in 2019 , attendances for surgical diseases were 2,313 versus 609 in 2020 , with a $74 \%$ reduction.

During period 1, 2, 3 and 4 emergency surgery was performed in 24 patients, compared to 60 cases in 2019, with a statistically significant drop of $60 \%$ (p value $<0.001)$. Decomposing the surgeries into categories for indications and applying the Wilcoxon sided test, a significant difference in the distribution of appendicitis ( 8 vs 20, p value $<0.001)$ and in the distribution of incarcerated hernias $(1$ vs $10, p$ value $<0.001)$ was found, as showed in Table 2 .

Table 2

Absolute number of surgeries in 2019 and 2020, clustered for disease 


\begin{tabular}{|c|c|c|c|c|c|c|c|c|c|c|c|}
\hline & 2019 & & & & & 2020 & & & & & \\
\hline Disease & Period & $\begin{array}{l}\text { Period } \\
2\end{array}$ & $\begin{array}{l}\text { Period } \\
3\end{array}$ & $\begin{array}{l}\text { Period } \\
4\end{array}$ & Total & $\begin{array}{l}\text { Period } \\
1\end{array}$ & $\begin{array}{l}\text { Period } \\
2\end{array}$ & $\begin{array}{l}\text { Period } \\
3\end{array}$ & $\begin{array}{l}\text { Period } \\
4\end{array}$ & Total & $\begin{array}{l}p \\
\text { value }\end{array}$ \\
\hline Appendicitis & 4 & 1 & 9 & 6 & 20 & 0 & 0 & 4 & 4 & 8 & $<0.001$ \\
\hline Cholecystitis & 0 & 0 & 2 & 0 & 2 & 1 & 0 & 1 & 0 & 2 & n.s. \\
\hline Diverticulitis & 1 & 0 & 1 & 0 & 2 & 0 & 0 & 0 & 0 & 0 & n.s. \\
\hline Intestinal perforation (non diverticulitis) & 2 & 1 & 0 & 1 & 4 & 0 & 0 & 2 & 0 & 2 & n.s. \\
\hline $\begin{array}{l}\text { Incarcerated inguinal hernia/ } \\
\text { Incarcerated umbilical or postoperative } \\
\text { hernia }\end{array}$ & 0 & 2 & 5 & 3 & 10 & 1 & 0 & 0 & 0 & 1 & $<0.001$ \\
\hline $\begin{array}{l}\text { Gastro-duodenal perforation/ } \\
\text { hemorrhage }\end{array}$ & 2 & 0 & 0 & 2 & 4 & 0 & 1 & 0 & 1 & 2 & n.s. \\
\hline Small bowel obstruction & 1 & 1 & 4 & 3 & 9 & 0 & 1 & 2 & 3 & 6 & n.s. \\
\hline $\begin{array}{l}\text { Colon } \\
\text { obstruction }\end{array}$ & 1 & 1 & 2 & 0 & 4 & 0 & 0 & 1 & 0 & 1 & n.s. \\
\hline Mesenteric ischemia & 0 & 0 & 1 & 1 & 2 & 0 & 0 & 0 & 0 & 0 & n.s. \\
\hline Abscess & 0 & 1 & 0 & 2 & 3 & 0 & 0 & 1 & 1 & 2 & n.s. \\
\hline TOTAL & 11 & 7 & 24 & 18 & 60 & 2 & 2 & 11 & 9 & 24 & $<0.002$ \\
\hline
\end{tabular}

n.s.: non significant

For medicine accesses, the drop was $21 \%$ in period $1,47 \%$ in period 2 and $49 \%$ in period 3 . Also specialist fast tracks showed an impressive drop: $81 \%$ in period 1 , and $96 \%$ in period 2 and 3 , with only a small drop reduction in period 4 (92\% reduction as compared to 2019).

In the fourth period, the drop showed a moderate reduction for medicine (40\%) and surgery (63\%), but it was still significant (Figure 2 )

Attendances for domestic violence had a mean $86 \%$ and $85 \%$ drop in period 2 and 3 , respectively, but only a $10 \%$ decrease in the fourth period as compared to 2019 .

Emergency psychiatric examinations decreased by $50 \%$ and $74 \%$ in the second and third period, and the trend went on in the fourth period (65\%).

In 2020 , deaths in ED increased by $50 \%, 280 \%$ and $238 \%$ through period $1-3$, and slightly reduced to $167 \%$ in period 4 , as compared to 2019 .

The percentage of patients who left the ED without being seen by a physician, or during the diagnostic process (LWBS), with respect to all the ED attendances, showed a significant drop in the second period, when the LWBS were the $2.8 \%$ of the ED attendances in 2020 vs $9.6 \%$ in 2019 , and in the third period ( $5.1 \%$ vs $7.8 \%$ ), while in the first period (7.2\% vs $8 \%$, in 2020 and 2019 respectively), and in the fourth period (6.2\% vs $7.8 \%$ ) the drops, though statistically significant, were less evident (Table 3).

\section{Table 3}

Absolute numbers and percentages of people who left the ED without being seen by a physician or during treatment (LWBS) in 2019 and in 2020 , with percentage of drops in 2020 compared to 2019. 


\begin{tabular}{|lllllllll|}
\hline & 2019 & & \multicolumn{7}{c|}{2020} \\
\hline Period & LWBS & All accesses & $\%$ & LWBS & All accesses & $\%$ & $\%$ drop \pm SE & p value \\
& $(\mathbf{N})$ & $(\mathbf{N})$ & & $(\mathbf{N})$ & $(\mathbf{N})$ & & & \\
\hline 1 & 250 & 3,108 & 8 & 125 & 1,715 & 7.2 & $52 \pm 5.96$ & $<0.001$ \\
\hline 2 & 265 & 2,761 & 9.6 & 22 & 776 & 2.8 & $92 \pm 0.43$ & $<0.001$ \\
\hline 3 & 473 & 6,030 & 7.8 & 83 & 1,616 & 5.1 & $82 \pm 1.02$ & $<0.001$ \\
\hline 4 & 277 & 3,565 & 7.8 & 81 & 1,308 & 6.2 & $69 \pm 1.22$ & $<0.001$ \\
\hline
\end{tabular}

Figure 3 in Supplemental material shows in details the daily drop for ED sub-specialist attendances.

\section{Discussion}

This study showed a significant decrease in the overall volume of ED attendances immediately before and during lockdown of $48.3 \%, 72.8 \%$ and $63.3 \%$ respectively, compared to the same time-interval in 2019. The drop was significant for surgical patients (74\%), all specialist fast tracks, psychiatry and domestic violence too. Accesses for medical complaints also decreased, but less than surgical diseases, due to the high influx of severe COVID-19 patients, which is reflected in the high patient mortality in the ED. Mortality had a mean increase of $259 \%$, and a peak in the second period, when Italy had the peak of infections and of hospital and ICU admissions for COVID-19.

ED attendances reduction, although more contained, was reported in the UK too, with a $25 \%$ fall in visits during -not before- the first week following lockdown [7].

A frequently cited index of ED functioning, i.e. the percentage of patients who leave the ED without being seen by a physician, or during the diagnostic process $[8,9]$, showed a decrease through all examined periods. To our knowledge, there is no published data about LWBS during mass casualty events such as pandemics. In our ED, the marked reduction compared to previous "normal" year clearly shows that people seeking care had severe conditions, not amenable to treatment outside the hospital. For all the people who do not ultimately receive medical advice, probably for minor complaints, faster alternative tracks should be implemented during pandemics, even in ad hoc facilities outside the hospitals.

Many aspects of the present study need explanation. For example, in our ED the trend in the reduction of visits began when it seemed that there were no infections yet in Milan, with $56 \%$ and $81 \%$ reduction in accesses for surgical and specialist fast track complaints. In general, it was likely that people may be worried of contracting COVID-19 in hospital. In particular, Emergency Departments are often crowded, and this could be true even in COVID-19 era, as stressed by media during all the pandemic. It is likely that many people with mild symptoms decided not to come to the ED thinking that hospitals were dangerous and unsafe places for non-COVID-19 patients. This is the case for admissions due to ophthalmologic, otolaryngological, urologic and orthopedic diseases. The reduction in attendances followed the ascending trend of SARS-CoV-2 infection.

For surgical attendances, the drop in minor traumatic injuries caused by traffic collisions is easily attributable to home confinement and to the drastic reduction in vehicle traffic, due to the lockdown started on March 8. Vehicles' circulation was allowed for essential workers only, or for serious emergency reasons, in every case with auto-certification and heavy fines in case of false declarations. On March 17, the Lombardy Government declared an overall $60 \%$ decrease of social mobility in the region [10].

For accidents at work, mostly trauma falls, the drop could be due to closure of building sites and factories. Fewer or no contact between people due to closure of places of socialization, with reduced alcohol and drugs use, can explain the reduced attendances of stab wounds due to street crimes like assaults. Such decrease has been reported in the USA, too [11]. However, this phenomenon should have been balanced by domestic violence, caused by home confinement of abused women and children, as it was reported in France [12] and the U.S. [13], but this was not the case in our hospital. Perhaps, these cases will merge when it will be easier for people to move and seek help, as evidenced by the increase in ED attendances in the fourth period.

But what about surgical emergency cases (infections, ischemia and obstruction), that must be dealt with promptly? The impact of COVID-19 outbreak on emergency surgery in Policlinico Hospital has been significant: compared to the same time periods in 2019, surgical interventions had a $60 \%$ drop in 2020. The decrease can only partially be explained by the redistribution of cases in hospital hub designed by the Lombardy Emergency Task Force, and dedicated to time-dependent diseases (trauma, cerebrovascular accidents, coronary disease). Ideally, the accesses for urgent and emergent conditions, such as abdominal infections, obstruction and ischemia should have been almost unchanged. On the contrary, emergency surgery for infection, such as appendicitis, cholecystitis and diverticulitis, was performed in 14 patients, compared to 24 cases in 2019, with a 42\% reduction. We did not observe a delay in presentation, as reported by a recent survey performed by a questionnaire sent to Italian hospitals practicing emergency surgery [14].

Before surgery, all the patients had an imaging-proven complicated appendicitis or cholecystitis, and all were tested for COVID-19. All had a laparoscopic approach, in contrast to initial advice against the utilization of laparoscopy in the COVID-19 era [15-17]. Although there is scarce evidence of airborne and particulate transmission in laparoscopy $[16,18]$, these possibilities cannot certainly be ruled out. This is the reason why many advise against the laparoscopic approach or, more adherent to current surgical practice, suggest to use devices to remove surgical smoke [19, 20], claiming that "the advantages of minimally invasive surgery may not need to be sacrificed in the current crisis"[16]. 
The reasons for the reduced hospital access for infectious surgical disease remains to be explained. We can speculate that people were not sent to the ED and were treated conservatively, i.e. with antibiotics, by their general practitioners. If this is the case, and we can know it from statistics in the future, the medical community should revaluate the role of out-of-hospital medical therapies in treating diseases traditionally considered of surgical interest. Inhospital non-operative management (NOM) has been suggested by recent literature for uncomplicated appendicitis, selected cholecystitis patients and colonic diverticulitis [21-27]. In the COVID-19 era, this strategy was suggested by many international recommendations [28-30] and has many advantages, first of all protecting patients and staff from possible intrahospital and in theatre virus transmission, save human resources and devices, and make new ICU beds available. Moreover, recent literature reported an unexpected high rate of postoperative complications and mortality even after elective surgery [31, 32], both for infected but asymptomatic patients before surgery and for patients contracting COVID-19 after surgery [31-33].

All the patients who had emergency surgery in Policlinico Hospital during the pandemics had swabs, and all were COVID-19 negative.

Bowel and gastro-duodenal perforations halved in 2020, accounting for 4 interventions vs 8 cases in 2019. Also surgery for incarcerated umbilical, inguinal and incisional hernia dropped to only one case, compared to 10 cases in 2019 . We may suppose that home-confinement, with reduction of physical activity and hard work, could contribute to the reduced surgeries for incarcerated hernia. However, in Spain an increase in surgery for incarcerated hernia [34] was reported, and we know that containment measures as self-isolation and home confinement were the same as those taken in Italy. For gastro-intestinal perforations we cannot find a convincing and plausible explanation. Covered duodenal perforations, which can be treated conservatively with nasogastric suction and antibiotics, usually are a minority of the observed cases, and it is hard to believe that such patients could stay at home and be cured only by fasting. The same for colon perforation, often caused by complicated cancer. Obstruction, another frequent complication of colon cancer, was an uncommon finding during COVID-19 outbreak. In one case endoscopic placement of an endoprosthesis allowed the postponement of surgery for two weeks.

Surgery for small bowel obstruction did not significantly change. Conservative treatment, with nasogastric suction, nil per os and intravenous fluids, was the treatment of choice for not more than 72 hours, as suggested by literature [35] and usually carried out in the Emergency Surgery Department of Policlinico Hospital. Surgery was performed when obstruction did not solve or contrast medium CT showed the need for intervention without delay.

Severe COVID-19 is associated with a marked inflammatory and prothrombotic state [36], but no cases of mesenteric ischemia were diagnosed and operated on in COVID-19 patients during the outbreak.

The study's results confirm the decrease in ED attendances for all medical and surgical complaints during the COVID-19 pandemic. The decrease in surgical patients was much more impressive and led to a significant reduction in emergency surgeries. Although some diseases might have been managed conservatively, if our data are confirmed in other settings, it would be important to know the consequences for patients that did not seek medical attention and for a possible rebound on the health care system.

\section{LIMITATIONS}

We must acknowledge some limitations of the present work. The study did not analytically analyzed the single diagnoses of ED access to assess what diseases were missing with respect to the previous year.

Moreover, no updated data about surgery in other hospitals of the metropolitan area of Milan are available, but informal communications between general and emergency surgeons confirm the drop in emergency surgeries.

Finally, patients might have dead at home for the complications of untreated surgical urgencies. However, at the moment it is difficult to assess the possible change in mortality rates for non-COVID19 diseases from national and regional death registries.

\section{Conclusions}

During the COVID-19 outbreak, indications for emergency surgery did not change with respect to previous periods. What changed was the volume of patients accessing to ED, and of surgery for urgent and emergent diseases. At the moment, it is not known if mortality of people who did not seek care for fear of contracting COVID-19 has risen during the pandemic. We also question if, in the near future, the impressive drop in the volume of ED attendances in the COVID period will result in a rebound of more severe disease left untreated in their early onset. Further studies are needed, hopefully at regional and national level, to understand if ED attendances and emergency surgeries drops during the COVID-19 pandemic resulted in an increase of mortality and unwanted complications in the population.

\section{Declarations}

Competing interests: The authors declare that they have no competing interests.

Ethical approval: Since all the analyses presented in this manuscript were based on anonymous administrative data, patient informed consent and Ethical Committee approval were not required in Italy.

\section{Abbreviations}

COVID-19: Corona VIrus Diseases 2019 
ED: Emergency Department

LWBS: Patients who left the ED without being seen

WHO: World Health Organization

SARS-CoV-2: Severe Acute Respiratory Syndrome-related CoronaVirus-2

NOM: Non-Operative management

\section{References}

[1] Grasselli G, Pesenti A, Cecconi M. Critical Care Utilization for the COVID-19 Outbreak in Lombardy, Italy: Early Experience and Forecast During an Emergency Response [published online ahead of print, 2020 Mar 13]. JAMA. 2020;10.1001/jama.2020.4031. doi:10.1001/jama.2020.4031 (accessed March 30, 2020)

[2] Italian National Civil Protection Department. COVID-19 Monitoring and data dashboard.

http://opendatadpc.maps.arcgis.com/apps/opsdashboard/index.html\#/b0c68bce2cce478eaac82fe38d4138b1 (accessed April 12, 2020)

[3] Decreto Regionale Lombardia n. 3353 del 13 marzo 2020-integrazione DGR 2906 dell'8 marzo 2020

[4] Updated Intercollegiate General Surgery Guidance on COVID-19 - Royal College of Surgeons. https://www.rcseng.ac.uk/coronavirus/joint-guidancefor-surgeons-v2, 2020 (accessed March 30, 2020)

[5] SAGES, SAGES and EAES Recommendations Regarding Surgical Response to COVID-19 Crisis - SAGES. https://www.sages.org/recommendationssurgicalresponse-covid-19, 2020 (accessed April 4, 2020)

[6] Coimbra R, Edwards S, Kurihara H, et al. European Society of Trauma and Emergency Surgery (ESTES) recommendations for trauma and emergency surgery preparation during times of COVID-19 infection. Eur J Trauma Emerg Surg. 2020;46(3):505-510. doi:10.1007/s00068-020-01364-7 (accessed April $20,2020)$

[7] Thornton J. Covid-19: A\&E visits in England fall by 25\% in week after lockdown. BMJ 2020;369.m1401 doi:10.1136/bmj.m1401 (accessed April 7, 2020)

[8] Ortiz-Barrios MA and Alfaro-Saiz JJ. Methodological Approaches to Support Process Improvement in Emergency Departments: A Systematic Review. Int. J. Environ. Res. Public Health 2020, 17, 2664; doi:10.3390/ijerph17082664

[9] Peterson SM, Harbertson CA, Scheulen JJ, Kelen GD. Trends and Characterization of Academic Emergency Department Patient Visits: A Five-year Review. Acad Emerg Med. 2019;26(4):410-419. doi:10.1111/acem.13550

[10] "Coronavirus, Gallera e Sala: "Monitoriamo gli spostamenti dei lombardi, ora sono al 40\% rispetto alla normalità. Dato ancora troppo alto"' (video) (in Italian). Fatto Quotidiano. 17 March 2020

[11] Nelson B. The positive effects of covid-19. BMJ 2020;369:m1785 doi: 10.1136/bmj.m1785 (Published 4 May 2020). (accessed May 6, 2020)

[12] https:///www.lejdd.fr/Politique/info-jdd-violences-sexistes-les-signalements-multiplies-par-5-pendant-le-confinement-3959404 (accessed May 30,2020)

[13] Dazio S, Briceno F and Tarma M.. Crime drops around the world as COVID-19 keeps people inside.

https://apnews.com/bbb7adc88d3fa067c5c1b5c72a1a8aa6 (accessed May 30, 2020)

[14] Patriti A, Baiocchi GL, Catena F, et al., on behalf of the Associazione Chirurghi Ospedalieri Italiani (ACOI). Emergency general surgery in Italy during the COVID-19 outbreak: first survey from the real life. World J Emerg Surg. 2020;15(1):36. doi:10.1186/s13017-020-00314-3 (accessed May 24, 2020)

[15] Zheng MH, Boni L, Fingerhut A (2020) Minimally invasive surgery and the novel coronavirus outbreak: lessons learned from Italy. Ann Surg. https ://doi.org/10.1097/SLA.00000 00000003924 (accessed April 4, 2020)

[16] Mowbray NG, Ansell J, Horwood J, et al. Safe management of surgical smoke in the age of COVID-19 [published online ahead of print, 2020 May 3]. Br J Surg. 2020;10.1002/bjs.11679. doi:10.1002/bjs.11679 (accessed May 3, 2020)

[17] Francis N, Dort J, Cho E, et al. SAGES and EAES recommendations for minimally invasive surgery during COVID-19 pandemic. Surg Endosc. 2020;34(6):2327-2331. doi:10.1007/s00464-020-07565-w (accessed April 24, 2020)

[18] About the Coronavirus Disease 2019 (COVID-19). American College of Surgery. COVID-19: considerations for optimum surgeon protection before, during, and after operation. 2020. https ://www.facs.org/covid -19/clinical-guidance/surge on-prote ction (accessed April 24, 2020) 
[19] Zago M, Uranues S, Chiarelli ME, et al. Enhancing safety of laparoscopic surgery in COVID-19 era: clinical experience with low-cost filtration devices [published online ahead of print, 2020 Jun 1]. Eur J Trauma Emerg Surg. 2020;1-5. doi:10.1007/s00068-020-01413-1 (accessed June 1, 2020)

[20] Mintz Y, Arezzo A, Boni L et al. The risk of COVID-19 transmission by laparoscopic smoke may be lower than for laparotomy: a narrative review. Surgical Endoscopy 2020. 10.1007/s00464-020-07652-y (accessed May 27,2020)

[21] Flum DR. Clinical practice. Acute appendicitis-appendectomy or the "antibiotics first" strategy [published correction appears in N Engl J Med. 2015 Jun 4;372(23):2274]. N Engl J Med. 2015;372(20):1937-1943.

[22] Allievi N, Harbi A, Ceresoli M et al. Acute appendicitis:still a surgical disease? Results from a propensity-based outcome analysis of conservative versus surgical management from a prospective database. World J Surg 2017;41:2697-705

[23] Di Saverio, S., Podda, M., De Simone, B. et al. Diagnosis and treatment of acute appendicitis: 2020 update of the WSES Jerusalem guidelines. World J Emerg Surg 2020;15, 27

[24] Ansaloni L, Pisano M, Coccolini F et al. 2016 WSES guidelines on acute calculous cholecystitis. World J Emerg Surg 2016; 11: 25. 39

[25] Okamoto K, Suzuki K, Takada T, et al. Tokyo Guidelines 2018: flowchart for the management of acute cholecystitis. J Hepatobiliary Pancreat Sci. 2018;25(1):55-72

[26] Pisano M, Ceresoli M, Cimbanassi S, et al. 2017 WSES and SICG guidelines on acute calcolous cholecystitis in elderly population. World J Emerg Surg. 2019;14:10.

[26] Sartelli M, Catena F, Ansaloni L et al. WSES guidelines for the management of acute left sided colonic diverticulitis in the emergency setting. World J Emerg Surg 2016; 11: 37- 41

[27] De Simone B, Chouillard E, Di Saverio S, et al. Emergency surgery during the COVID-19 pandemic: what you need to know for practice. Ann $R$ Coll Surg Engl. 2020;102(5):323-332. doi:10.1308/rcsann.2020.0097 (accessed May 2, 2020)

[28] Zizzo M, Bollino R, Castro Ruiz C, et al. Surgical management of suspected or confirmed SARS-CoV-2 (COVID-19)-positive patients: a model stemming from the experience at Level III Hospital in Emilia-Romagna, Italy [published online ahead of print, 2020 Apr 28]. Eur J Trauma Emerg Surg. 2020;1-5. doi:10.1007/s00068-020-01377-2 (accessed May 2, 2020)

[29] Collard M, Lakkis Z, Loriau J et al. Antibiotics alone as an alternative to appendectomy for uncomplicated acute appendicitis in adults:changes in treatment modalities related to the COVID-19 heath crisis. J Visceral Surg 2020;doi.rg/10.1016/jviscsurg 2020.04.014 (accessed April 30, 2020)

[30] Aminian A, Safari S, Razeghian-Jahromi A, Ghorbani M, Delaney CP. COVID-19 Outbreak and Surgical Practice: Unexpected Fatality in Perioperative Period [published online ahead of print, 2020 Mar 26]. AnnSurg.2020;10.1097/SLA.0000000000003925.doi:10.1097/SLA.0000000000003925 (accessed April 30, 2020)

[31] COVIDSurg Collaborative. Mortality and pulmonary complications in patients undergoing surgery with perioperative SARS-CoV-2 infection: an international cohort study [published online ahead of print, 2020 May 29] [published correction appears in Lancet. 2020 Jun 9;:]. Lancet. 2020;S01406736(20)31182-X. doi:10.1016/S0140-6736(20)31182-X (accessed April 4, 2020)

[32] Lei S, Jiang F, Su W, et al. Clinical characteristics and outcomes of patients undergoing surgeries during the incubation period of COVID-19 infection [published online ahead of print, 2020 Apr 5]. EClinicalMedicine. 2020;21:100331. doi:10.1016/j.eclinm.2020.100331 (accessed April 10, 2020)

[34] Cano-Valderrama O, Morales X., Ferrigni C, et al. (2020). Reduction in emergency surgery activity during COVID-19 pandemic in three Spanish hospitals. British Journal of Surgery. 10.1002/bjs.11667. (accessed May 20, 2020)

[35] Ten Broek RP, Krielen P, Di Saverio S et al. Bologna guidelines for diagnosis and management of of adhesive small bowel obstruction (ASBO): 2017 update of the evidence-based guidelines from the World Society of Emergency Surgery ASBO working group. World J Emerg Surg 2018;13:24

[36] Huang C, Wang Y, Li X et al. Clinical features of patients infected with 2019 novel coronavirus in Wuhan, China. Lancet 2020;395:497-506 (accessed February 11,2020$)$

\section{Figures}




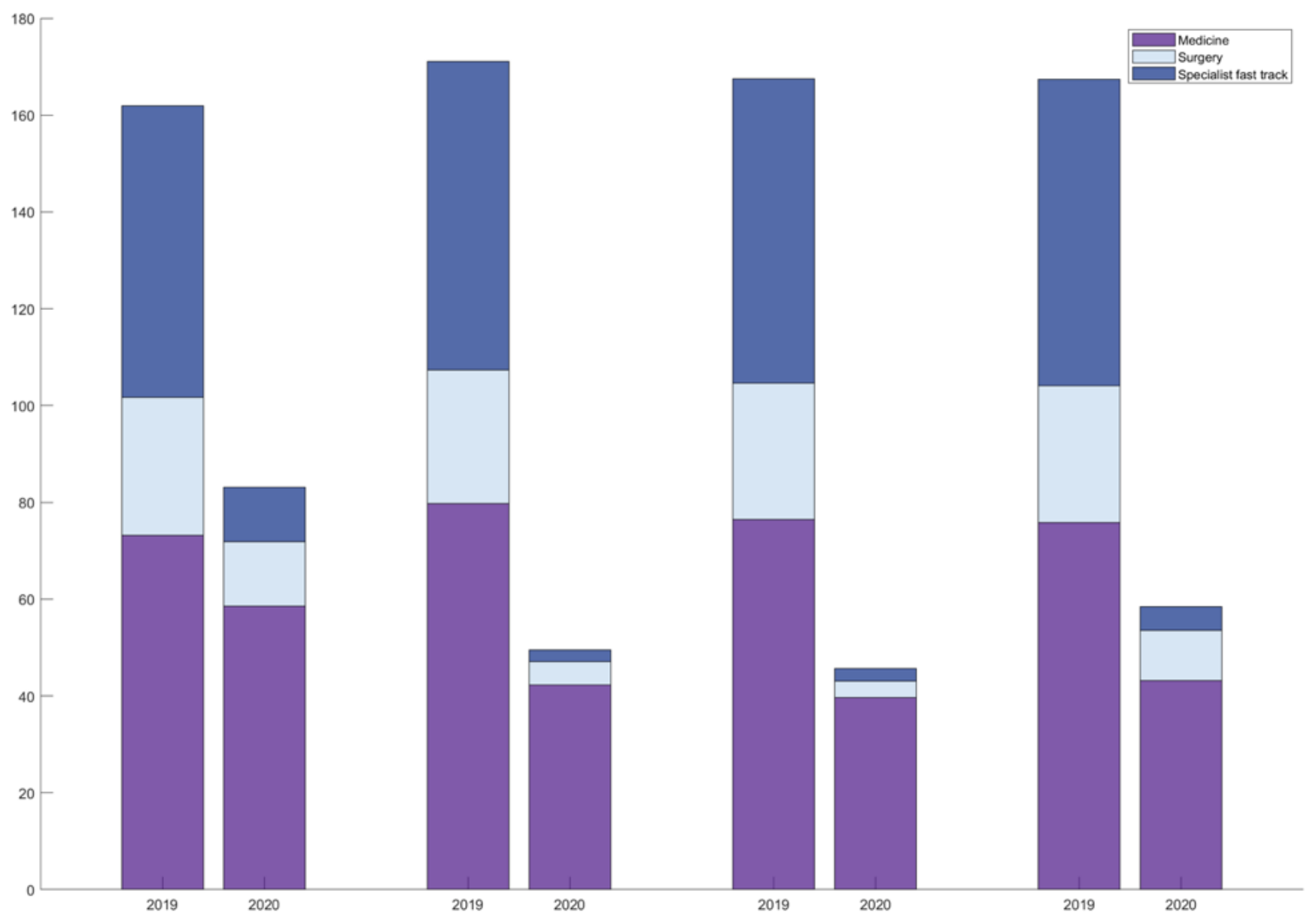

Figure 1

Per-period mean daily access for medicine, surgery and specialist fast track in 2019 and 2020. 


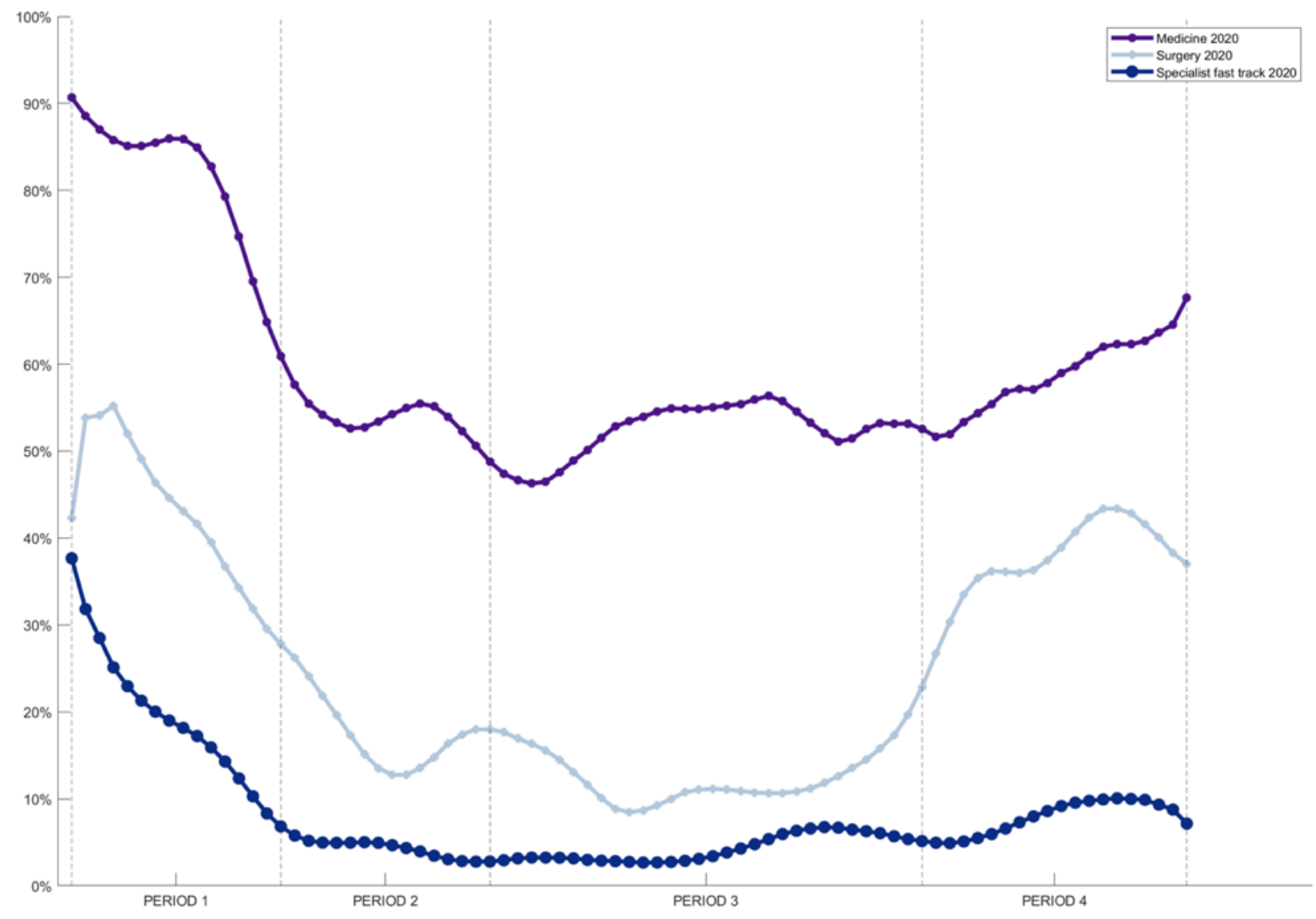

Since 2020 is a leap year, accesses in February 28, 2019, and February 29, 2020 have been averaged.

Figure 2

Daily accesses for medicine, surgery and specialist fast track in 2020 expressed as the percentage of accesses in the same days in 2019.

\section{Supplementary Files}

This is a list of supplementary files associated with this preprint. Click to download.

- SUPPLEMENTALMATERIAL.doc 